\title{
Health and Safety Issues of Industry Workmen
}

\author{
Fida Siddiqui \\ Department of Civil Engineering \\ Mehran University of Engineering \& \\ Technology, Jamshoro, Pakistan \\ fidasiddiqui2@gmail.com
}

\author{
Ali Raza Khoso \\ Department of Civil Engineering \\ Mehran University of Engineering \& Technology \\ Jamshoro, Pakistan \\ aliraza.khoso@faculty.muet.edu.pk
}

\author{
Muhammad Akram Akhund \\ Department of Civil Engineering \\ ISRA University, \\ Hyderabad, Pakistan \\ akhund42@gmail.com
}

\author{
Aftab Hameed Memon \\ Department of Civil Engineering \\ Quaid-e-Awam University of Engineering \\ Science and Technology, Pakistan \\ aftabm78@hotmail.com
}

\author{
Hafiz Usama Imad \\ Department of Civil Engineering \\ ISRA University \\ Hyderabad, Pakistan \\ usama.imad@isra.edu.pk
}

\begin{abstract}
Flour milling is considered the oldest trade industry, initiated at least 6000 years ago. Like every other industry, numerous problems arise during functioning and maintenance operations. The production process involves the breakdown of grains to separate their outer covering and inner endosperm grinding to fine flour particles. Workers serving in the industry have been in an environment exposed to flour dust. After conducting several interviews and a questionnaire survey to the workers and sales managers of flour mills within Hyderabad in Pakistan, the workforce was found to be suffering from sensitization, occupational asthma, allergic rhinitis, obstructive lung diseases and eye infection. The core reason was the inhaled and swallowed flour dust. The majority of the respondents highlighted the improper flour milling process including intake and final product collection systems as the main causes of these health problems. The other part of the research work revealed that the majority of safety issues emerged due to the unavailability, the failure to use and the unawareness of personal protective equipment. Regarding the suggestions received during the survey from respective stakeholders, the health and safety issues can be controlled by improving feeding and collection systems and by wearing personal protective equipment.
\end{abstract}

Keywords-flour milling industry; health issues; personal protective equipment; safety concerns

\section{INTRODUCTION}

Flour dust has been of an imperative importance in flour milling process from the beginning. Several food industries including flour mills are facing the issue of exposure to flour dust. In developing countries, due to quick industrialization and fruitless measures for pollution control, indoor air pollution has become a main problem and the lack of public awareness of the impacts of indoor air pollutants on human health has increased it. Flour mill workers are expected to be exposed to such threats for 8-10 hours per day averagely [1]. A handful of studies showed that exposure to flour dust causes respiratory symptoms and is highly related to lung function damage [2-3]. In mills, grinding operation is the initial point of danger in processing grains, as grain is ground into fine particles of dustlike size and flammable concentrations are unavoidable [4]. Studies also show that potential allergens implicated are the components of wheat flour contaminants, such as weevils, mite sand moulds, or flour additives, especially yeast and aspergillus derived amylase [5]. Flour dust can cause sensitization, occupational asthma and allergic rhinitis [3]. In flour mills, there is potential exposure to grain dust [6]. Individuals who work in dusty environments face the risk of inhaling particulate materials which may lead to adverse respiratory effects [7]. In the baking industry, exposure to wheat flour dust may cause respiratory illness of different nature and severity, ranging from simple irritant symptoms to allergic rhinitis or occupational asthma. Sensitization to such allergens may result in increased prevalence of respiratory symptoms and airway hyper responsiveness [5].

Authors in [8] investigated the effect of exposure to flour dust on respiratory symptoms and lung function of flour mill workers and estimated the additive effect of smoking on pulmonary function. Two hundred male workers with current exposure to flour dust and two hundred non-exposed male workers as a control group were interviewed and answered a self-designed study questionnaire and the parameters of their pulmonary function were measured. Results indicated that respiratory symptoms such as cough, expectoration, wheezing and shortness of breath, were significantly $(p<0.0001)$ higher among exposed workers when compared to unexposed workers. Occupational hazards are inherent for individuals working with machines, especially when the machines are rotating and are unprotected. Mishaps associated with flour mills are infrequent most likely due to the small setup involving less manpower or due to partition that is usually made between the machine and the worker reducing the accidental involvement in the machine. Nevertheless, workers in the setup may, at times, involve in accidents [9-10]. Another leading problem in several industries, including flour milling, is the un-availability and unawareness of personal protective equipment (PPE). Several accidents occur because workers 
ignore safety measures during working hours. In many of the industries of developing countries, the unavailability of PPE is very common. In some industries, PPE is available but there are no regarding rules and regulations and no training is provided to ensure the use of PPE. Study of some companies in Nigeria's north-eastern states shows that the causes of accidents in companies are the carelessness of the workers and to some extent the lack of machinery maintenance [11].

Chronic obstructive pulmonary disease (COPD) is a global health concern. According to the World Health Organization (WHO), it is presently the sixth leading cause of death in the world. Indoor and outdoor air pollution and tobacco exposure are the main reasons. The burden of COPD in Asia is at present greater than that in the developed western countries [12]. There are about 75,000 workers in the United Kingdom baking industry [13] with some 24,000 in occupations where exposure to flour is likely [14]. A smaller but unidentified number of workers are involved in milling and wheat processing. Results from the surveillance of work-related and occupational respiratory disease (SWORD) project suggest an annual incidence of occupational asthma among bakery workers of at least one per 1000 [15]. Aerosols like fine particles, $\mathrm{SO}_{2}$ and $\mathrm{CO}$ gases can enter into the trachea-bronchial and create frustrating effects in the respiratory tract. If exposed to pollution, the usual response of an individual would be in the forms of bronchospasm, cough, excessive production of mucus etc. and can lead to emphysema, fibrosis of the lungs if exposure is chronic [16].

The current study on flour mills revealed that workers are at substantial risk with two main problems causing severe health issues and accidents. The first one is the improper flour milling process including intake and final products collection systems. The second problem is the unawareness and unavailability of PPE. The intake system of feeding the wheat and the final product collection methods were the main causes of exposure to dispersed flour dust. There was neither a controlled mechanical system for opening the gate of intake hopper nor proper underground pits to place the bulk amount of wheat. On the other side, the concrete tanks built to collect and store the final products were uncovered. Packing was carried out simultaneously. Workers were required to put wheat from the intake hopper simultaneously when the bucket elevator was lifting grains to drum sieve. During this entire feeding process intake, hopper's gate remained open and ample amount of dust was found rushing out and was directly inhaled. Allergic rhinitis, asthma, obstructive lung diseases, and sensitization were found common in workers of these flour mills, in different ratios, elaborated in the result section. This study has been carried out on the flour mills of Hyderabad city, Pakistan in early 2017.

\section{MATERIALS AND METHODS}

Numerous studies were taken into consideration to finalize the issues of flour mills' workmen to solidify our work. Initially, various reasons which contribute to the raising of accident rate and health issues at flour mills were identified from previously conducted research works throughout the world. As a part of the preliminary survey, unstructured interviews of workers, technicians, and managers of flour mills were conducted to finalize factors. A questionnaire was then prepared. It contained the factors to analyze the severity level and the workers were asked to fill up. Collected data was analyzed by average index (AI) technique utilizing the statistical package for the social sciences (SPSS). The collaboration of flour milling technical, administrative and working staff helped to map out possible remedial measures and recommendations. The pictorial view of the methodology is shown in Figure 1.

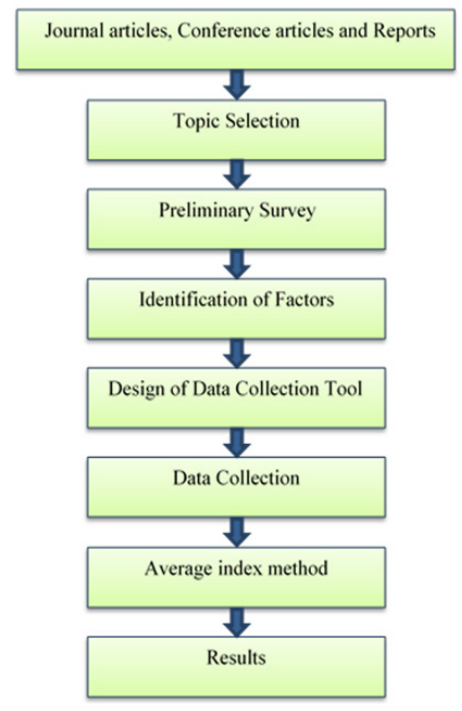

Fig. 1. Methodological flowchart

\section{RESULTS AND DISCUSSION}

The AI value, calculated with the equations adopted from [17-18] is used in this research for factor analysis. The respondents were asked to encircle the appropriate item according to their experience. Data was collected by a survey conducted through questionnaires. Quantitative data analysis was done based on the Likert scale (1-5). Various demographical variables were inquired from the respondents along with the main focused health and safety issues of the industry. The respondents were a variety of people: workers, technicians and sales managers and their respective percentages are mentioned in Figure 2 whereas Figure 3 reports the number of years of experience of the respondents.

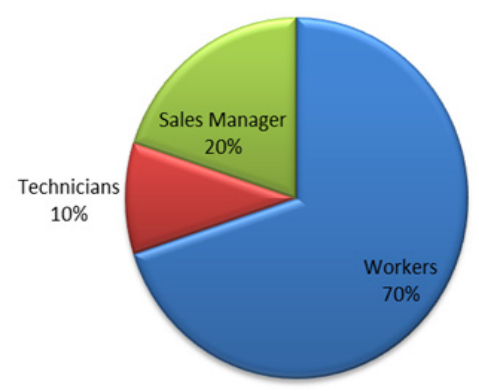

Fig. 2. Occupation level 
Regarding the demographic portion, the bar-chart shown in Figure 4 depicts that majority (16) of people were uneducated as they were at a 'worker' grade in the industry. Twelve workers were educated up to a primary level only. Collectively, technicians and sales managers only were found out to be educated up to the graduation level.

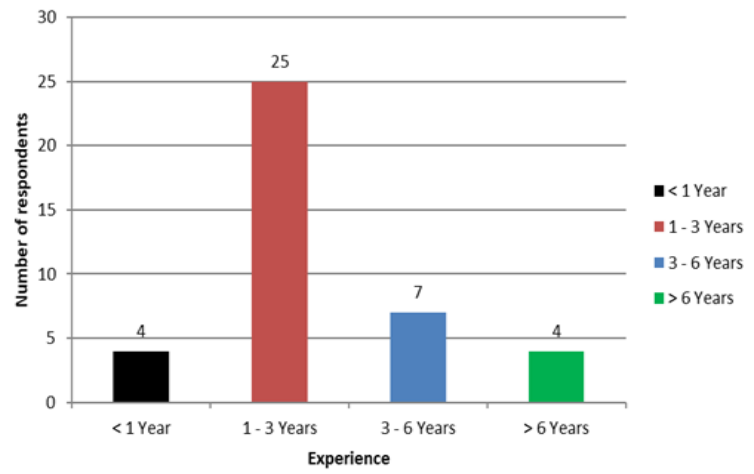

Fig. 3. Experience level

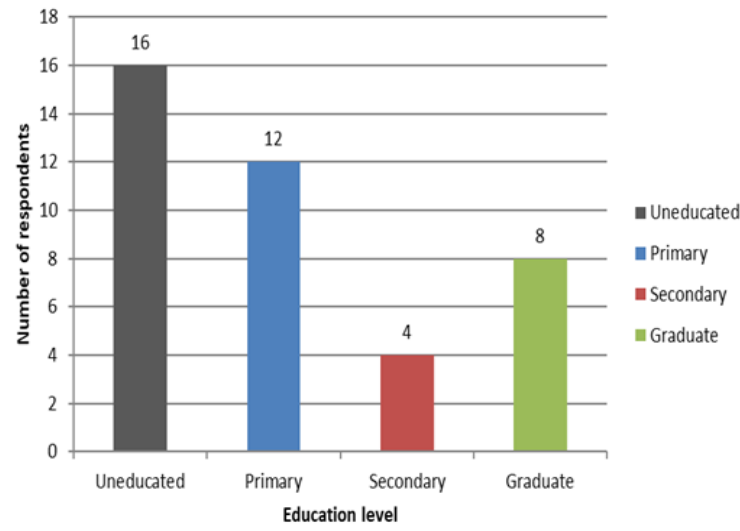

Fig. 4. Education level

Table I enlists all the factors that contribute to accidents and health issues at flour mills along with their corresponding AI values. Data analysis showed that dispersion of flour dust is found common in all flour mills with the highest severity level $(\mathrm{AI}=4.3) .36$ out of 40 stakeholders collectively identified this factor as severe and very severe for creating health concerns. This dust is inhaled, swallowed and absorbed by workers leading to various diseases. Results reveal that the reasons behind dispersion of flour dust were the improper feeding system of grain and the improper final product collection system as shown in Figure 6. The second, third and fourth most critical factors are failure, unavailability and unawareness to use PPE with average index values of $3.72,3.65$ and 3.25 respectively. These three factors lead to accidents. As the owners of these small-scale flour mills are just concerned with the monetary benefits, no use of PPE was observed. Because of being less educated, almost all workers were unaware of the safety measures which could be taken on site during working. That's why 24 respondents marked 'failure to use PPE' as 'severe'. Apart from these reasons, the other leading causes of accidents were found to be the improper and heavy lifting of flour bags by the workers. Many workers were less experienced so, they weren't good at proper and easy techniques for lifting objects. Figure 5 highlights the three main processing systems that contribute in flour dust dispersion. Respondents had the choice to mark multiple options if more than one system contributed to the indoor air pollution. The systems marked come under category of flour milling process and nearly all workers, technicians and sales managers marked flour milling process as a cause of flour dust dispersion. Thus, the systems need to be assessed properly in order to avoid such problems.

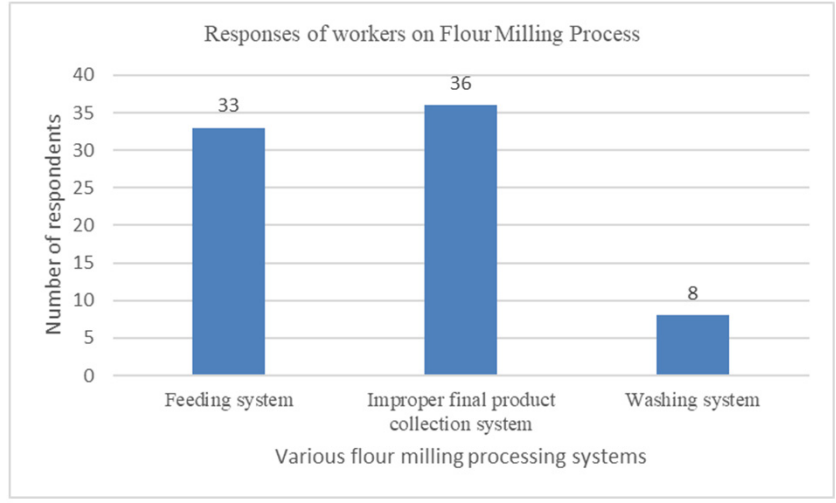

Fig. 5. The systems contributing in flour dust dispersion

The preliminary survey performed at different flour mills in the region of Hyderabad consisted of questions regarding whether the workers were suffering from any health issues before joining their milling job. As the workers' experience ranged from 3 to 6 years, the majority of people readily responded that they faced these issues during their current job. As shown in Figure 7, workers were found suffering from different health issues such as allergic rhinitis, sensitization, occupational asthma and lung diseases mainly because of the flour dust inhaled during working hours. It is known that smoking also leads to various diseases, so a question was deliberately asked in the questionnaire regarding the smoking habits of workers. Analysis showed that only 5\% people were smokers which further strengthened the results of multiple health issues due to flour dust dispersion.

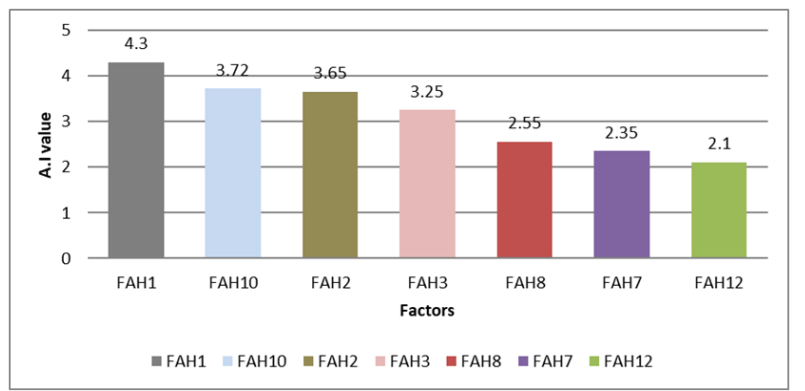

Fig. 6. Critical factors those contribute to accidents and health issues at flourmills 
TABLE I. FACTORS CONTRIBUTING HEALTH AND SAFETY ISSUES

\begin{tabular}{|c|c|c|c|c|c|c|c|c|c|}
\hline \# & Factors & NS & SS & MS & $\mathbf{S}$ & $\mathbf{V S}$ & AI & Median & Rank \\
\hline $\mathrm{FAH}_{3}$ & PPE unawareness & 4 & 3 & 16 & 13 & 4 & 3.25 & 3.00 & 04 \\
\hline $\mathrm{FAH}_{5}$ & Noise sparking & 30 & 10 & 0 & 0 & 0 & 1.25 & 1.00 & 13 \\
\hline $\mathrm{FAH}_{6}$ & Sparking & 39 & 1 & 0 & 0 & 0 & 1.02 & 1.00 & 17 \\
\hline $\mathrm{FAH}_{7}$ & Improper lifting & 1 & 24 & 15 & 0 & 0 & 2.35 & 2.00 & 06 \\
\hline $\mathrm{FAH}_{10}$ & Failure to use PPE & 1 & 1 & 10 & 24 & 4 & 3.72 & 4.00 & 02 \\
\hline $\mathrm{FAH}_{11}$ & Lifting greasy objects & 32 & 8 & 0 & 0 & 0 & 1.20 & 1.00 & 14 \\
\hline $\mathrm{FAH}_{12}$ & Poor physique & 9 & 18 & 13 & 0 & 0 & 2.10 & 2.00 & 07 \\
\hline $\mathrm{FAH}_{13}$ & Objects having sharp edges & 30 & 10 & 0 & 0 & 0 & 1.25 & 1.00 & 13 \\
\hline $\mathrm{FAH}_{14}$ & Foot injuries due to dropped objects & 9 & 30 & 1 & 0 & 0 & 1.8 & 2.00 & 10 \\
\hline $\mathrm{FAH}_{19}$ & Falling in open tank without cover in level floor & 33 & 7 & 0 & 0 & 0 & 1.17 & 1.00 & 15 \\
\hline $\mathrm{FAH}_{20}$ & Accidents due to poor lighting & 32 & 6 & 2 & 0 & 0 & 1.25 & 1.00 & 13 \\
\hline
\end{tabular}

\section{REMEDIAL MEASURES TO CONTROL HEALTH AND SAFETY ISSUES}

The following measures are suggested:

1. The mill owners must ensure proper use of PPE.

2. The workers should demand the usa of PPE to minimize the risk of accidents.

3. Health and safety seminars should be conducted at a local level in languages understood by the workers.

4. Intake and collection system should be modified.

5. Processing facilities should be designed in a way that there should be a proper mechanical system of opening the gate of intake hopper.

6. Underground pits of reasonable height should be built or grain intake pits on the ground should be designed to feed the bulk amount of wheat at once to reduce continuous exposure to dust.

7. The tank, where final products are collected and packed should be covered in order to prevent flour dispersion in the surrounding environment.

8. Simultaneous packing and production should be avoided by increasing the size of final product collection tanks without compromising demand and supply.

\section{CONCLUSION AND RECOMENDATIONS}

Being the oldest one at the global level, flour milling industry is frequently prone to hazard issues especially at local and regional levels that are not being monitored properly. This cross-sectional study is based on unstructured interviews and questionnaires. It was carried out in order to identify the health and safety issues of flour milling industry workmen of Hyderabad, Sindh. Out of numerous factors, dispersed flour dust and ignorance towards PPE are highly ranked. Workers did suffer from severe health impacts like allergic rhinitis, occupational asthma and lung diseases mainly because of flour dust dispersion. The reasons behind the sources for dispersion of flour dust were feeding and final product collection systems. On the other hand, PPE were unavailable and hence no such awareness amongst workers was observed. By considering the literature review and data evaluated during this study all problems should be addressed with keen importance at each concerned level. A study can be performed at a regional level again by developing a monitoring system for the period after the implementation of remedial measures suggested in the current study, to analyze the results.

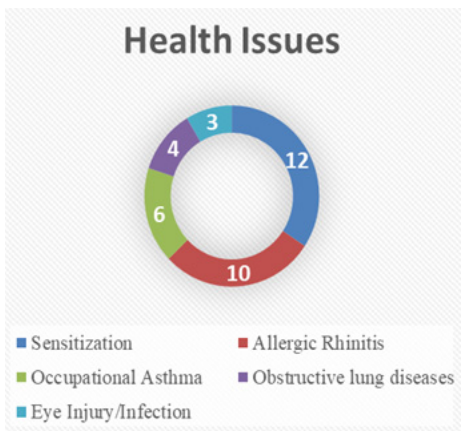

Fig. 7. Common workmen diseases in flourmill industry

\section{REFERENCES}

[1] N. D. Wagh, B. G. Pachpande, V. S. Patel, S. B. Attarde, S. T. Ingle, "The influence of workplace environment on lung function of flour mill workers in Jalgaon urban center", Journal of Occupational Health, Vol. 48, No. 5, pp. 396-401, 2006

[2] N. A. H. Ajeel, A. K. Al-Yassen, "Work-related allergic disorders among flour mill workers", The Medical Journal of Basrah University, Vol. 25, No. 1, pp. 29-32, 2007 
[3] S. K. Dhillon, R. Bassi, R. G. Thamman, "Effect of flour dust on lung volumes and capacities in flour mill workers", National Journal of Integrated Research in Medicine, Vol. 3, No. 2, pp. 91-95, 2012

[4] M. Mittal, "Explosion Hazard and Safety in Industries Handling Grain Products", Journal of Engineering Research and Studies, Vol. 1, No. 3, pp. 1-11, 2013

[5] A. B. Bohadana, N. Massin, P. Wild, M. N. Kolopp, J. P. Toamain, "Respiratory symptoms and airway responsiveness in apparently healthy workers exposed to flour dust", The European Respiratory Journal, Vol. 7, No. 6, pp. 1070-1076, 1994

[6] T. A. Smith, G. Parker, T. Hussain, "Respiratory symptoms and wheat flour exposure: a study of flour millers", Occupational Medicine, Vol. 50. No. 1, pp. 25-29, 2000

[7] A. M. Said, E. B. Abdel Fattah, A. A. M. Almawardi, "Effects on respiratory system due to exposure to wheat flour", Egyptian Journal of Chest Diseases and Tuberculosis, Vol. 66, No. 3, pp. 537-548, 2017

[8] M. A. Mohammadien, M. T. Hussein, R. T. El-Sokkary, "Effects of exposure to flour dust on respiratory symptoms and pulmonary function of mill workers", Egyptian Journal of Chest Diseases and Tuberculosis, Vol. 62, Vol. 4, pp. 745-753, 2013

[9] R. C. Oginyi, O. S. Mbam, C. O. Abojei, O. N. James, "Assessment of Occupational Health Hazard and the Use of Safety Measures among Rice Mill Workers in Ebonyi State, Nigeria", World Applied Sciences Journal, Vol. 35, No. 7, pp. 1133-1141, 2017

[10] R. Bardale, S. Dhawane, "Fatal avulsion of scalp: Unusual occurrence at flourmill", Journal of Indian Academy of Forensic Medicine, Vol. 30, No. 3, pp. 151-152, 2008

[11] A. O. Inegbenebor, "The Effect of Accidents On The Productivity Of Some Companies In North-Eastern States Of Nigeria", J. Soc. \& Mgt. Sci, Vol. 6, pp. 46-52, 1999

[12] B. Iftikhar, M. H. Khan, H. Hussain, M. Iqbal, G. S. Jadoon, "Relationship between silica dust exposure and chronic obstructive pulmonary disease in workers of dust generating industries of district Peshawar", Gomal Journal of Medical Sciences, Vol. 7, No. 1, pp. 4650,2004

[13] U.K. Office for National Statistics, Labour Force Survey 2017, available at: http://www.ilo.org/surveydata/index.php/catalog/1807/ study-description, 2017

[14] HSE, A Baker's Dozen: Thirteen Essentials for Health and Safety in Bakeries, HSE Books, 2003

[15] P. Cullinan, D. Lowson, M. J. Nieuwenhuijsen, C. Sandiford, R. D. Tee, K. M. Venables, J. C. McDonald, A. J. Newman Taylor, "Work related symptoms, sensitisation, and estimated exposure in workers not previously exposed to flour", Occupational and Environmental Medicine, Vol. 51, No. 9, pp. 579-583, 1994

[16] G. M. Latha, K. Sarala, S. Gouroju, "Effect of Construction and Flour Mill Air Pollution in Rural Area", International Journal of Integrative Medical Sciences, Vol. 2, No. 2, pp. 70-77, 2015

[17] J. M. Hussin, I. A. Rahman, A. H. Memon, "The way forward in sustainable construction: issues and challenges", International Journal of Advances in Applied Sciences, Vol. 2, No. 1, pp. 15-24, 2013

[18] A. R. Khoso, M. A. Akhund, A. H. Memon, F. Siddiqui, S. H. Khahro, "Health and Safety of Hyderabad Industries' Labor. Causes and Awareness", Engineering, Technology \& Applied Science Research, Vol. 7, No. 6, pp. 2334-2339, 2017 